\title{
Regional modelling of polycyclic aromatic hydrocarbons: WRF-Chem-PAH model development and East Asia case studies
}

\author{
Qing Mu ${ }^{1}$, Gerhard Lammel ${ }^{1,2}$, Christian N. Gencarelli ${ }^{3}$, Ian M. Hedgecock ${ }^{3}$, Ying Chen $^{1,4}$, Petra Přibylová2 \\ Monique Teich $^{4}$, Yuxuan Zhang ${ }^{1}$, Guangjie Zheng ${ }^{5}$, Dominik van Pinxteren ${ }^{4}$, Qiang Zhang ${ }^{6}$, Hartmut Herrmann ${ }^{4}$, \\ Manabu Shiraiwa ${ }^{1,7}$, Peter Spichtinger $^{8}$, Hang Su $^{1,9}$, Ulrich Pöschl ${ }^{1}$, and Yafang Cheng ${ }^{1,9}$ \\ ${ }^{1}$ Multiphase Chemistry Department, Max Planck Institute for Chemistry, Mainz, Germany \\ ${ }^{2}$ Research Centre for Toxic Compounds in the Environment, Masaryk University, Brno, Czech Republic \\ ${ }^{3}$ CNR-Institute of Atmospheric Pollution Research, Division of Rende, Rende, Italy \\ ${ }^{4}$ Leibniz Institute for Tropospheric Research, Leipzig, Germany \\ ${ }^{5}$ Brookhaven National Laboratory, Brookhaven, USA \\ ${ }^{6}$ Ministry of Education Key Laboratory for Earth System Modeling, Department of Earth System Science, \\ Tsinghua University, Beijing, China \\ ${ }^{7}$ Department of Chemistry, University of California, Irvine, USA \\ ${ }^{8}$ Institute for Atmospheric Physics, Johannes Gutenberg University, Mainz, Germany \\ ${ }^{9}$ Institute for Environmental and Climate Research, Jinan University, Guangzhou, China
}

Correspondence to: Yafang Cheng (yafang.cheng@mpic.de) and Gerhard Lammel (g.lammel@ mpic.de)

Received: 15 June 2017 - Discussion started: 20 June 2017

Revised: 21 September 2017 - Accepted: 22 September 2017 - Published: 13 October 2017

\begin{abstract}
Polycyclic aromatic hydrocarbons (PAHs) are hazardous pollutants, with increasing emissions in pace with economic development in East Asia, but their distribution and fate in the atmosphere are not yet well understood. We extended the regional atmospheric chemistry model WRFChem (Weather Research Forecast model with Chemistry module) to comprehensively study the atmospheric distribution and the fate of low-concentration, slowly degrading semivolatile compounds. The WRF-Chem-PAH model reflects the state-of-the-art understanding of current PAHs studies with several new or updated features. It was applied for PAHs covering a wide range of volatility and hydrophobicity, i.e. phenanthrene, chrysene and benzo[ $[a]$ pyrene, in East Asia. Temporally highly resolved PAH concentrations and particulate mass fractions were evaluated against observations. The WRF-Chem-PAH model is able to reasonably well simulate the concentration levels and particulate mass fractions of PAHs near the sources and at a remote outflow region of East Asia, in high spatial and temporal resolutions. Sensitivity study shows that the heterogeneous reaction with ozone and the homogeneous reaction with the nitrate radical significantly influence the fate and distributions
\end{abstract}

of PAHs. The methods to implement new species and to correct the transport problems can be applied to other newly implemented species in WRF-Chem.

\section{Introduction}

Polycyclic aromatic hydrocarbons (PAHs), released into the atmosphere as by product of all kinds of combustion processes, are harmful for human health via inhalation as well as ingestion pathways (WHO, 2003; Lv et al., 2016) and for ecosystems (Hylland, 2006). In the atmospheric environment PAHs are partly readily degradable, partly undergo longrange transport and reach remote areas (Keyte et al., 2013). PAHs have been included in the United Nations Economic Commission for Europe Convention on Long-range Transboundary Air Pollution and Protocol on Persistent Organic Pollutants. Hazardous substances, mostly benzo $[a]$ pyrene $(\mathrm{BaP})$, are criteria pollutants in many countries, including the European Union, USA and Japan. The United States Environmental Protection Agency (USEPA) prioritised 16 PAHs in the 1970s, which have been mostly targeted in the environ- 
ment since then, but this selection is questionable considering toxicity and occurrence of PAHs (Andersson and Achten, 2015).

As PAHs are mainly generated from incomplete combustion of carbonaceous bio- and fossil fuels, their emissions increase dramatically in Asia due to rapid economic development and energy consumption. According to Zhang and Tao (2009), the total emission of the 16 PAH compounds listed in the USEPA priority control list was about $290 \mathrm{Gg} \mathrm{yr}^{-1}$ in Asia in the year 2004, accounting for more than half of total global emissions. High emissions of PAHs in Asia pose a hazard to the ecosystems and human health on an intercontinental or even global scale (Hung et al., 2005).

In an attempt to elucidate the spatiotemporal distributions of PAH ambient concentrations and processes governing their atmospheric fate, several numerical modelling studies have been published. Lagrangian frameworks have been used for Europe (van Jaarsveld et al., 1997; Halsall et al., 2001) and China (Lang et al., 2007, 2008). Other studies focused on the multicompartmental behaviour using box models (Yaffe et al., 2001; Prevedouros et al., 2004, 2008). Eulerian chemical transport models have been developed and applied for regions, i.e. Europe (Aulinger et al., 2007; Matthias et al., 2009; Bieser et al., 2012; San Jose et al., 2013; Efstathiou et al., 2016), North America (Galarneau et al., 2014) and East Asia (Zhang et al., 2009, 2011a, b; Inomata et al., 2012, 2013), or on the global scale (Sehili and Lammel, 2007; Lammel et al., 2009; Friedman and Selin, 2012; Friedman et al., 2014a, b; Shen et al., 2014; Shrivastava et al., 2017). The aforementioned studies differ in many respects relating to the PAH species examined, the temporal variability of their emissions, the spatial and process resolutions of the models. However, the up-to-date representations of complex PAH processes (e.g. gas-particle partitioning, heterogeneous chemistry and re-volatilisation) are not reflected in the previous modelling studies, nor have these processes been evaluated against limited monitoring data. In addition, a high temporal resolution like the diurnal cycle is not seen.

Since its initial release in 2002, Weather Research Forecast model with Chemistry module (WRF-Chem) has been widely applied and verified for regional air quality (Zhang et al., 2010, 2013) and climate (Liao et al., 2014; Yahya et al., 2016) study with high temporal and spatial resolutions. Compared to the previous PAH modelling studies, this work is unique in four aspects: (1) it includes all relevant state-of-the-art processes of PAH into WRF-Chem which are important for its cycling in the atmospheric environment over land (i.e. new heterogeneous degradation scheme, several oxidants in homogeneous degradation processes, and revolatilisation from soil, among others), (2) predicts and validates against observed gas- and particulate-phase PAH concentrations separately, (3) validates atmospheric concentrations and particulate mass fraction against diurnal variable PAH observations, and (4) explores the significance of PAH heterogeneous reaction with ozone $\left(\mathrm{O}_{3}\right)$ and gas-phase reaction with nitrate radical $\left(\mathrm{NO}_{3}\right)$.

\section{Model development}

WRF-Chem-PAH is based on the open-source community model WRF-Chem (version 3.6.1), which is a fully coupled, "online" regional model with integrated meteorological, gasphase chemistry, and aerosol components (Grell et al., 2005). It is built on the Advanced Research WRF core, which handles the dynamics, physics, and transport processes. Gasphase chemistry and aerosol schemes are integrated over the same time step as transport processes, allowing for full coupling between the schemes. The short chemistry time step also made the model ideal for studying short-lived PAH species with high levels of spatial heterogeneity.

By considering the compatibility with the WRF-Chem Kinetic PreProcessor (KPP) (Sandu et al., 2003; Sandu and Sander, 2006) and similarities of PAH chemistry to volatile organic aerosol formations, we have made the following choices. The Regional Atmospheric Chemistry Mechanism (RACM) (Stockwell et al., 1997) is used for homogeneous gas-phase reactions. The aerosol module includes the Modal Aerosol Dynamics Model for Europe (MADE) (Ackermann et al., 1998) for the inorganic fraction, and the Secondary Organic Aerosol Model (SORGAM) (Schell et al., 2001) for the secondary organic aerosols. MADE/SORGAM in WRFChem uses the modal approach with three log-normally distributed modes (nuclei, accumulation and coarse mode). All pollutant species normally simulated in the standard RACM/SORGAM mechanism are also simulated in WRFChem-PAH. In order to include PAHs (and organics in general) in air-soil gas exchange processes, the Noah soil scheme (Chen and Dudhia, 2001) is utilised.

\subsection{Framework}

Figure 1 shows the framework of PAH extensions in WRFChem, where modules/subroutines that have been modified in terms of embedding PAH extensions are listed. All the new variables related to emissions and concentration fields of PAHs and those intermediate variables used in different chemical and physical processes, such as air-soil gas exchange, gas-phase/heterogeneous reactions, cloud scavenging, dry/wet deposition, advective transport and cumulus convection, are first defined in registry.chem and then included in respective sub-modules/routines.

The subroutine chem_driver is the main driver for handling chemistry-related tasks on a particular time step, including emissions, photolysis, gas- and particulate-phase reactions, convective transport, cloud chemistry, and dry/wet depositions. Based on the existing structure, all the chemical reactions involving gaseous and particulate PAHs mentioned in Sect. 2.2.1 and 2.2.2 have been added to 


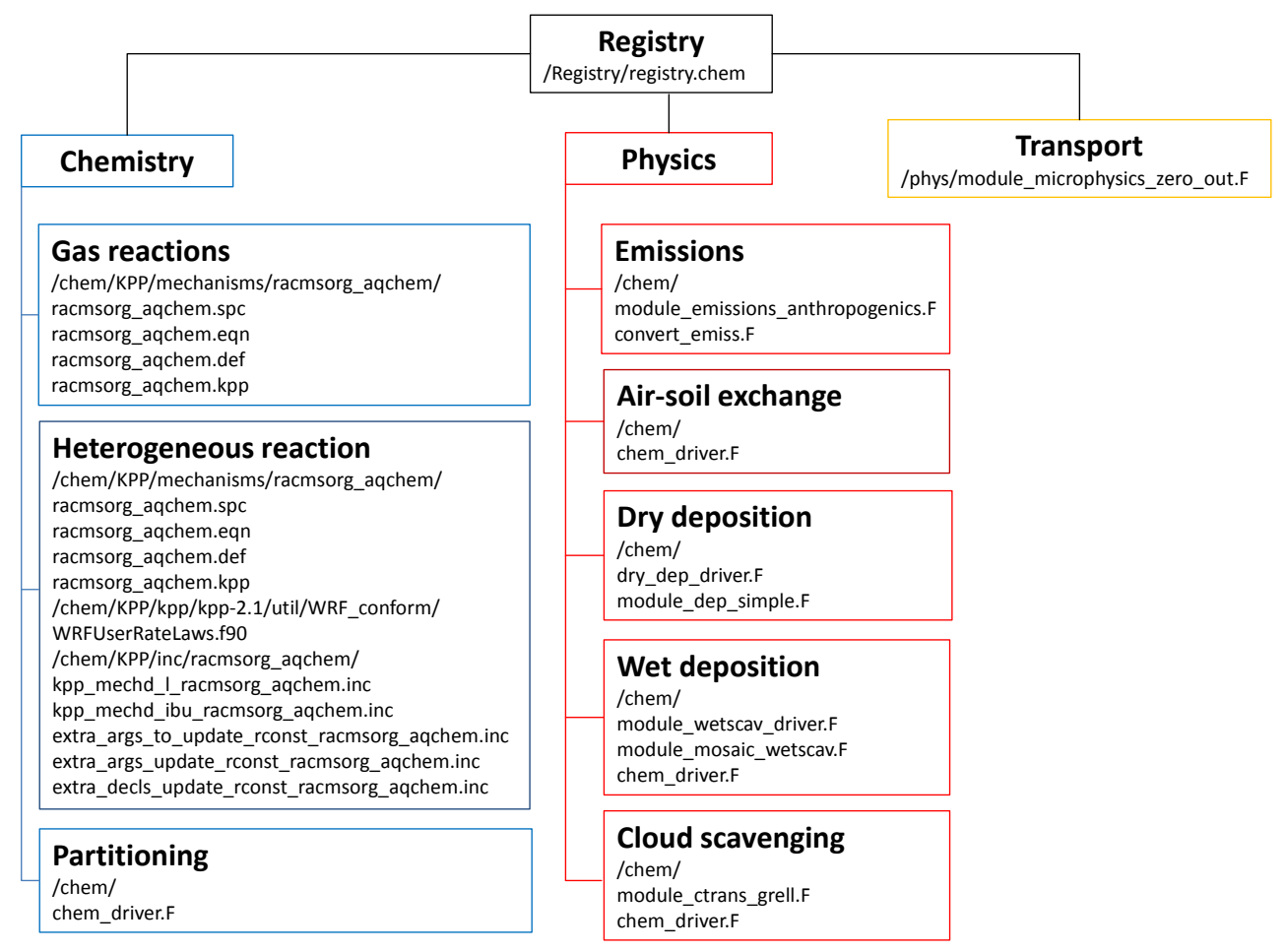

Figure 1. Framework of PAH extensions in WRF-Chem.

the RACMSORG_AQCHEM chemical mechanism by using KPP and the WRF-Chem KPP Coupler (Salzmann and Lawrence, 2006). Fixed rate coefficients are used for gas-phase reactions, while for heterogeneous reactions oxidant/temperature/humidity-dependent functions are formulated. Gas-particle partitioning of semivolatile PAHs (and organic compounds in general) is implemented based on substance-specific empiric equilibrium relationships in addition to the MADE/SORGAM module. Dry deposition, wet deposition and wet scavenging from cumulus convection are calculated in the respective subroutines, using the dry deposition velocity and the fraction of gaseous species dissolved in cloud water calculated in module_dep_simple and module_mosaic_wetscav, respectively. The air-soil gas exchange for organic compounds (secondary emissions) is implemented in addition to the primary emission module.

The simulated PAHs in our current WRF-Chem-PAH model include phenanthrene (PHE), chrysene (CHR) and $\mathrm{BaP}$, representing volatile, semivolatile and non-volatile $\mathrm{PAH}$ compounds, respectively. The WRF-Chem-PAH framework is not limited to these three species, and in general, all semivolatile compounds can be similarly implemented following our practices.

\subsection{Atmospheric processes of PAHs}

\subsubsection{Gas-phase reactions}

Reactions of gas-phase PAHs with hydroxyl radical $(\mathrm{OH})$, $\mathrm{NO}_{3}$ and $\mathrm{O}_{3}$ are considered in this model. While $\mathrm{NO}_{3}$ reactions appear to be less significant than $\mathrm{OH}$ reactions as the main PAH degradation process, the observed considerably high nitro-PAH yields suggest that nighttime reactions of PAHs with $\mathrm{NO}_{3}$ may be a significant contributor of these compounds in the atmosphere (Keyte et al., 2013). The significance of $\mathrm{NO}_{3}$ oxidation is further discussed in Sect. 6 . Here, the PAH oxidative loss is calculated as a second-order process using the model-predicted $\mathrm{OH}$ and $\mathrm{NO}_{3}$ concentration (Table 1). At this stage, PAH reaction products are not tracked in the model.

\subsubsection{Heterogeneous degradation of particulate BaP}

In this study, we have developed and applied a more elaborate parameterisation of the heterogeneous reaction kinetics of $\mathrm{BaP}$ degradation by ozone as a function of temperature and relative humidity based on the experimental data of Zhou et al. (2013) and the kinetic multi-layer model KM-SUB (Shiraiwa et al., 2010). Our model approach and parameterisation build on a Langmuir-Hinshelwood reaction mechanism involving the decomposition of ozone and formation of longlived reactive oxygen intermediates (Shiraiwa et al., 2011; Berkemeier et al., 2016). Table S2 in the Supplement lists the 
parameterisations of the reaction rates. Text S1 in the Supplement reviews previous study of the heterogeneous degradation of BaP.

\subsubsection{Gas-particle partitioning}

The unmodified (conventional) configuration of WRF-Chem uses a thermodynamic equilibrium scheme (SORGAM) to simulate gas-to-particle mass distribution of condensable and water-soluble species (Binkowski and Roselle, 2003). This approach is inappropriate for semivolatile and hydrophobic substances. Instead, empiric equilibrium partitioning expressions for PAHs are applied. We consider the absorption processes and chemically specific adsorption processes, both of which were found to be significant contributors to PAH gasparticle partitioning (Dachs and Eisenreich, 2000; Lohmann and Lammel, 2004).

We use a second equilibrium partitioning expression, which accounts for two contributions, absorption into organic matter and adsorption onto black carbon (BC) (Dachs and Eisenreich, 2000):

$K_{\mathrm{p}}=10^{-12}\left(\frac{1.5 f_{\mathrm{oc}}}{\rho_{\mathrm{oct}} K_{\mathrm{OA}}}+f_{\mathrm{bc}} K_{\mathrm{SA}}\right)=\frac{\sum c / c_{\mathrm{TSP}}}{c_{\mathrm{g}}}$,

$\theta=\left(1+\frac{1}{K_{\mathrm{p}} c_{\mathrm{TSP}}}\right)^{-1}$,

where $\rho_{\text {oct }}$ is the bulk density of octanol $\left(0.82 \mathrm{~kg} \mathrm{~L}^{-1}\right), f_{\text {oc }}$ is the organic carbon (OC) fraction of the particulate matter (the 1.5 multiplier converts OC to organic matter, which is assumed to be well represented by octanol), $K_{\mathrm{OA}}$ is the octanol-air partition coefficient (dimensionless, temperature dependent; Odabasi et al., 2006), $f_{\mathrm{bc}}$ is the $\mathrm{BC}$ fraction of the particulate matter, $K_{\mathrm{SA}}$ is the soot-air partition coefficient $\left(\mathrm{L} \mathrm{kg}^{-1}\right), \sum c_{\mathrm{p}}$ is the particulate PAH concentration across all the size bins ( $\left.\mathrm{ng} \mathrm{m}^{-3}\right), c_{\mathrm{TSP}}$ is the total particulate matter concentration $\left(\mu \mathrm{g} \mathrm{m}^{-3}\right)$, and $c_{\mathrm{g}}$ is the gas-phase concentration $\left(\mathrm{ng} \mathrm{m}^{-3}\right)$.

Since direct $K_{\mathrm{SA}}$ measurements are not available for PAHs, soot-air partitioning coefficients $\left(K_{\mathrm{SA}} \mathrm{L} \mathrm{kg}^{-1}\right)$ are estimated as the ratios of soot-water $\left(K_{\mathrm{SW}}\right.$; Jonker and Koelmans, 2002) and the air-water $\left(K_{\mathrm{AW}}\right)$ partitioning coefficients (dimensionless, temperature dependent; Bamford et al., 1999). Values of $K_{\mathrm{SW}}$ vary substantially (up to a factor of 47 for the PAHs considered here) among relevant soot. The representative values for atmospheric $\mathrm{BC}$ are determined by weighting the reported $K_{\mathrm{SW}}$ values by the contribution of their related combustion processes to the total emitted fine particulate matter used in the inventory of Galarneau et al. (2007).

\subsubsection{Air-soil gas exchange}

Semivolatile PAHs are subject to revolatilisation (Lammel et al., 2009; Galarneau et al., 2014). An air-soil gas exchange module is therefore included in WRF-Chem-PAH.

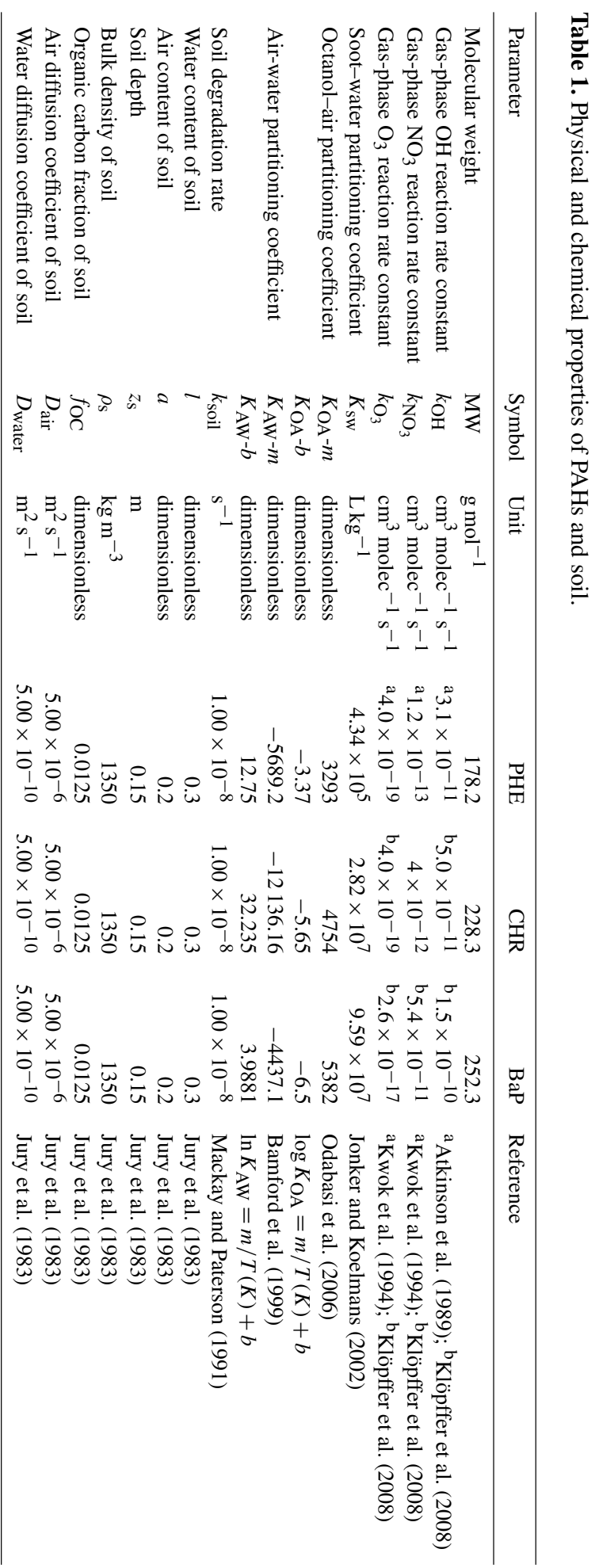


Air-soil gas exchange is parameterised following Strand and Hov (1996), which is based on Jury et al. (1983).

Model soil is a $0.15 \mathrm{~m}$ thick layer consisting of fixed volumes of soil organic matter, air and water. The soil layer is assumed to have the standard properties suggested by Jury et al. (1983) (Table 1). The change in PAH concentrations in soil/air, $c_{\mathrm{s}} / c_{\mathrm{a}}$, with time is expressed by

$$
\begin{aligned}
\frac{\partial c_{\mathrm{s}}}{\partial t} & =\frac{1}{z_{\mathrm{s}}}\left(F_{\mathrm{exc}, \text { soil }}+F_{\mathrm{wet}}\right)-k_{\mathrm{soil}} c_{\mathrm{s}}, \\
\frac{\partial c_{\mathrm{a}}}{\partial t} & =-\frac{1}{z_{\mathrm{a}}} F_{\text {exc, soil }},
\end{aligned}
$$

where $z_{\mathrm{s}}$ and $z_{\mathrm{a}}$ are the soil and atmospheric layer depths (m), respectively, $F_{\text {exc,soil }}$ is the air-soil gas exchange flux, $F_{\text {wet }}$ is the wet deposition flux, and $k_{\text {soil }}$ is the degradation rate in soil. The air-soil gas exchange flux is given by

$F_{\text {exc, soil }}=v_{\mathrm{s}}\left(c_{\mathrm{a}}-\frac{c_{\mathrm{s}}}{K_{\text {soil-air }}}\right)$,

where $v_{\mathrm{s}}$ is the exchange velocity, $c_{\mathrm{a}}$ is the PAH concentrations in air, and $K_{\text {soil-air }}$ is the partitioning coefficient between soil and air. The exchange velocity is given by

$v_{\mathrm{s}}=\frac{D_{\mathrm{air}} a^{10 / 3}(1-l-a)^{-2}+D_{\mathrm{water}} l^{10 / 3} K_{\mathrm{WA}}(1-l-a)^{-2}}{z_{\mathrm{s}} / 2}$,

where $D_{\text {air }}$ is the air diffusion coefficient, $D_{\text {water }}$ is the liquid diffusion coefficient, $K_{\mathrm{WA}}$ is the water-air partitioning coefficient depending on the soil temperature and equals the inverse of $K_{\mathrm{AW}}$, and $l$ and $a$ are the water and air fractions in soil, respectively. Partitioning between soil and air is given by Karickhoff (1981):

$K_{\text {soil-air }}=4.11 \times 10^{-4} \times \rho_{\mathrm{s}} f_{\mathrm{oc}} K_{\mathrm{OA}}$,

where $\rho_{\mathrm{s}}$ is the soil density, $f_{\mathrm{oc}}$ is the soil OC fraction and $4.11 \times 10^{-4}$ is a constant with units of $\mathrm{m}^{3} \mathrm{~kg}^{-1}$. PAHs are subject to biodegradation in soil, processes which are actually not well quantified. The degradation rate in soil $k_{\text {soil }}$ is estimated to be $10^{-8} \mathrm{~s}^{-1}$ based on a laboratory model ecosystems study (Lu et al., 1977), following a global PAH model (Friedman et al., 2014a, b).

Due to a lack of monitoring data, the PAH concentrations in soil are initialised by the global multicompartmental model output: a pseudo-steady state of anthracene (ANT), fluoranthene (FLT) and BaP concentrations in the soil compartment had been safely reached by a global simulation over 10 years with $2.8^{\circ} \times 2.8^{\circ}$ horizontal resolution (Lammel et al., 2009). PHE/CHR concentrations in soil are scaled from ANT/FLT according to the ratio upon primary emission. Figure S1 in the Supplement shows the air-soil gas exchange flux at a receptor site based on the above air-soil exchange scheme.

\subsubsection{Wet and dry depositions}

Dry deposition of gas-phase species in WRF-Chem is treated using the standard resistance approach (Wesely, 1989). The original WRF-Chem routines have been adapted to include the deposition of gas-phase PAH compounds, and the deposition flux is calculated from the product of the deposition velocity and gaseous PAH concentration in the lowermost model level. We consider the particulate-phase PAH species to be bound to the atmospheric particulate matter in the accumulation mode, whose dry deposition flux is calculated using WRF-Chem particulate deposition parameterisations.

The model accounts for wet deposition of PAH species through the schemes for gas and particulate convective transport, in-cloud and below-cloud scavenging of PAH species (sub-grid resolution, following the UCI (University of California, Irvine) chemistry transport model; Neu and Prather, 2012).

\section{Modification of transport scheme for low-concentration species}

The transport of BaP seems stopped (Fig. 2a) when we follow the WRF-Chem manual's suggestion by running with monotonic advection (chem, moist, scalar_adv_opt=2) while the transport of other chemical species behaves normally, e.g. BC, as shown in Fig. 2d. This is because the atmospheric concentration of $\mathrm{BaP}$ is too low, down to $10^{-9}$ to $10^{-12}$ ppmv. Other species are dealt with similarly, when artificially brought to extremely low concentrations, as confirmed for $\mathrm{BC}$ : the species does not undergo transport when dividing the $\mathrm{BC}$ concentration by $10^{10}$ before and then multiplying by $10^{10}$ after the advection subroutine. Figure $2 \mathrm{c}$ and $\mathrm{d}$ show the clear differences between the transportation of $\mathrm{BC}$ in these two cases. Furthermore, the near-source concentration of $\mathrm{BaP}$ is too low compared with the observation, because in the unmodified (conventional) transport non-zero $\mathrm{BaP}$ concentrations in air are limited to the immediate vicinities to strong sources and undergo fast degradation.

One of the important features of how the chemical transport model (Chem) couples with WRF in the WRF-Chem model is that the transport of chemical species is done by WRF. In WRF, monotonic advection is not a positive definite option, so that mp_zero_out $=2$ is usually set to make sure that the transport tendency of all the moisture variables will not grow below zero. To this end, the mp_zero_out_thresh is set as suggested to a small value of $10^{-8}$, and the transport tendency of moisture variables will be mapped to 0 when concentrations are smaller than mp_zero_out_thresh. In the coupled WRF-Chem model, when dealing with chemical transport, WRF advection module treats all the chemical species as if they are moisture variables following the same criterion of exceedance of mp_zero_out_thresh. This is usually not a problem, because the concentrations of species 

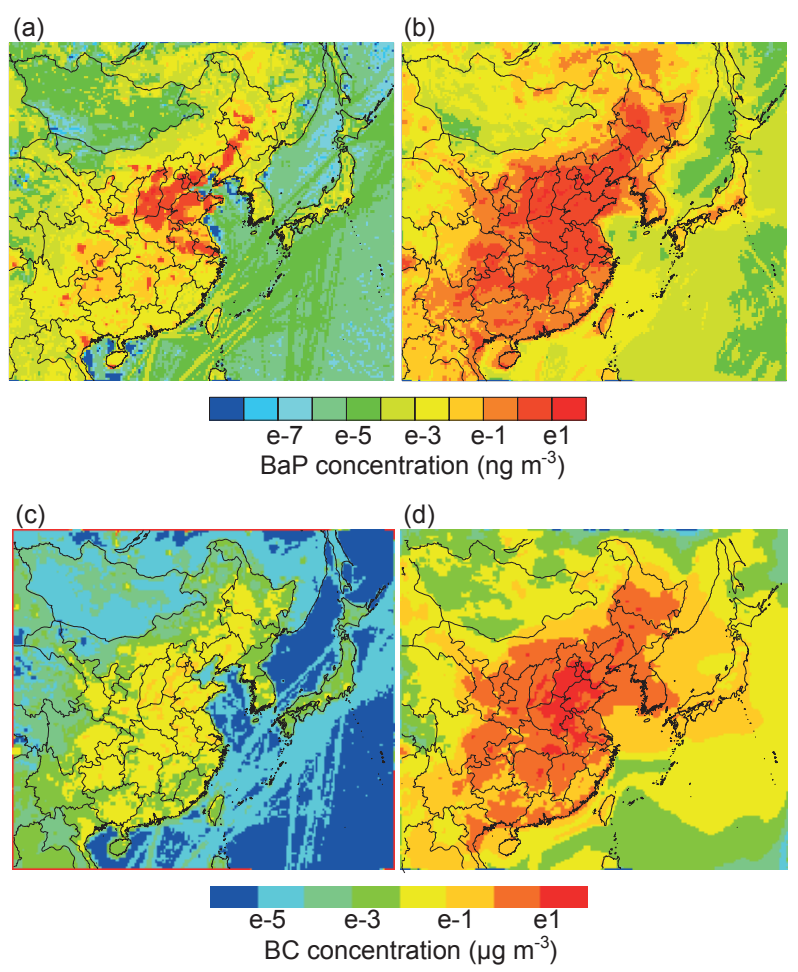

Figure 2. Simulated near-ground concentrations of $\mathrm{BaP}$ with (a) conventional transport scheme and (b) modified transport scheme for low-concentration species, and BC with (c) scaled low concentration and (d) normal concentration with conventional transport scheme averaged on 14 February 2003.

transported are in general higher than this threshold. However, it is not the case for $\mathrm{BaP}$, and the threshold truncates the $\mathrm{BaP}$ concentration and its transport tendency is forced to 0 and thus no transport occurs. To cope with this, we set mp_zero_out_thresh $=10^{-22}$ for PAHs species but leave it to $10^{-8}$ to moisture variables and all other chemical species. After this modification in advective transportation, $\mathrm{BaP}$ adequately undergoes transport in the model and the near-source concentration of $\mathrm{BaP}$ is elevated too (Fig. 2b). This solution can be applied to all newly implemented low-concentration species in WRF-Chem.

\section{Case study in East Asia}

\subsection{Model configuration}

To apply the WRF-Chem-PAH model, we configured a domain that covers East China and Japan $\left(15-55^{\circ} \mathrm{N}\right.$, 95$155^{\circ} \mathrm{E}$ ) with a horizontal resolution of $27 \mathrm{~km}$ by $27 \mathrm{~km}$ and 39 vertical layers up to $0.01 \mathrm{hPa}$. The spatial coverage of the domain is shown in Fig. 2.

The physics options applied in this study are summarised as follows (also see Table S1): the Purdue-Lin scheme (Lin et al., 1983) is used for microphysics, which includes six classes of hydrometeors (water vapour, cloud water, rain, cloud ice, snow and graupel). The planetary boundary layer is parameterised by the Mellor-Yamada-Janjić scheme (Janjic, 1994). It describes vertical sub-grid-scale fluxes due to eddy transport in the whole atmospheric column, while the horizontal eddy diffusivity is calculated with a Smagorinsky first-order closure. The surface layer parameterisation employed is the Eta Similarity surface layer scheme (Janjic, 1994). The land surface model to describe interactions between the soil and atmosphere is Noah Land Surface Model (Chen and Dudhia, 2001). The Grell 3D ensemble scheme (Grell and Devenyi, 2002) is used for cumulus parameterisation. The long- and shortwave radiation is calculated online with rapid radiative transfer model (Mlawer et al., 1997) and the Goddard schemes (Chou and Suarez, 1994), respectively. Photolysis rates are calculated using the Fast-J photolysis scheme (Wild et al., 2000) and updated every $60 \mathrm{~min}$.

For simulation of standard aerosol precursors and aerosol species in the WRF-Chem model, anthropogenic emissions for $\mathrm{NO}_{x}, \mathrm{CO}$, non-methane volatile organic compounds, $\mathrm{SO}_{2}, \mathrm{NH}_{3}, \mathrm{BC}$, and $\mathrm{OC}$ are taken from the EDGARHTAP global monthly inventory (http://edgar.jrc.ec.europa. eu/national_reported_data/htap.php) in the year 2010. The emissions of BC and OC in 2010 are further extrapolated to simulation year based on annual scaling factors taken from $\mathrm{Lu}$ et al. (2011), while no annual changes have been applied to emissions of other species. The EDGAR-HTAP inventory has a horizontal resolution of $0.1^{\circ}$. Hereby, biomass burning emissions are from the monthly Quick Fire Emissions Dataset (QFED) (Darmenov and Silva, 2013). Biogenic volatile organic compounds emissions are calculated from the Model of Emissions of Gases and Aerosols from Nature (MEGAN) (Guenther et al., 2006). Anthropogenic PAH emissions are re-gridded from a $0.1^{\circ} \times 0.1^{\circ}$ global annual PAH emission inventory for the year 2008, with 69 detailed source types (Shen et al., 2013). For specific simulation period, inter-annual scaling factors in the simulated domain are taken from Shen et al. (2013), based on historical fuel consumption data and IPCC SRES A1 scenario supposing a future world of rapid economic growth. Monthly scaling factors are taken from Zhang and Tao (2008). A diurnal cycle of the PAH emissions are applied with two maxima, around 08:00 and 19:00 local time, following that of BC. Biogenic contributions to PAH emission have been neglected. Figure S2 shows the average distributions of PHE, CHR and BaP emissions in July 2013. Figure S3 shows the inter-annual, monthly and hourly scaling factors of PAH.

Meteorological initial and boundary conditions are based on the National Center for Environmental Prediction Final Analysis' (NCEP-FNL) reanalysis data. Meteorology (temperature, horizontal wind, and moisture) is nudged at all vertical levels. Chemical initial and boundary conditions of standard species are from the global Model for Ozone and Related Chemical Tracers (MOZART-4) (Emmons et al., 2010), simulations performed using $1.9^{\circ} \times 2.5^{\circ}$ horizontal resolu- 
tions. Initial PAH concentrations at all lateral boundaries are set to zero because China is the dominant emission country. To reach a steady-state equilibrium concentration of PAHs in air, a spin-up time of $48 \mathrm{~h}$ is used.

\subsection{Model evaluation}

The WRF-Chem-PAH model is developed to capture the PAH transport episode in higher temporal and spatial resolution, i.e. in diurnal to daily scales and in both concentration level and particulate mass fraction. To this end, two sets of continuous PAH field campaign data with at least daily resolution and in both gaseous and particulate phases are chosen.

The first dataset provides both daytime and nighttime samples. As part of the Program of Campaigns of Air Quality Research in Beijing and Surrounding Region (CAREBeijing) 2013 campaign, measurement was made at the Xianghe Atmospheric Observatory $\left(39.80^{\circ} \mathrm{N}, 116.96^{\circ} \mathrm{E}\right)$. The Xianghe site is located in a PAH near-source area, $45 \mathrm{~km}$ southeast of Beijing and $70 \mathrm{~km}$ northwest of Tianjin (Fig. S2). The site is surrounded by residential suburban areas and distanced some $5 \mathrm{~km}$ from the local town centre. Particulate- and gasphase samples were collected twice a day (daytime samples 08:00-18:00 LT; nighttime samples 20:00-06:00 LT) during 11-22 July 2013. EC and OC samples of $\mathrm{PM}_{10}$ were also collected separately twice a day (daytime samples: 06:0018:00 LT; nighttime samples: 18:00-06:00 LT on the following morning) at the same site, which are important to evaluate gas/particle partition scheme of semivolatile PAHs. Details of the sampling methods and data quality control are described in Text S2.

Another PAH observation dataset is taken at the Gosan station $\left(33.28^{\circ} \mathrm{N}, 126.17^{\circ} \mathrm{E} ; 72 \mathrm{~m}\right.$ above sea level) on Jeju Island, in the northern part of the East China Sea, about $100 \mathrm{~km}$ south of the Korean Peninsula (Fig. S2). Gosan is a representative background site and an ideal location for studying long-range transport of air pollutants in East Asia (Han et al., 2006). Although the Gosan observation covers a long period from November 2001 to August 2003 (Kim et al., 2007, 2012), due to the high computational cost of WRF-Chem, we focus on an intensive measurement period (14-25 February 2003) with continuous gas- and particulate-phase PAHs (daily samples of 08:00-08:00 LT in the following morning) to represent a polluted continental outflow in East Asia in wintertime. However, to further demonstrate the general model performance in a seasonal scale, we make additional simulation for a continuous summer period 6-17 June 2003. Details of sampling and analysis methods are given in Kim et al. (2012).

\subsubsection{Evaluation at the near-source areas}

PAH diurnal variabilities are well captured for both gas- and particulate-phase species at the Xianghe site, with correlation coefficients of $0.42-0.69$ (Fig. 3, Table S3) compared
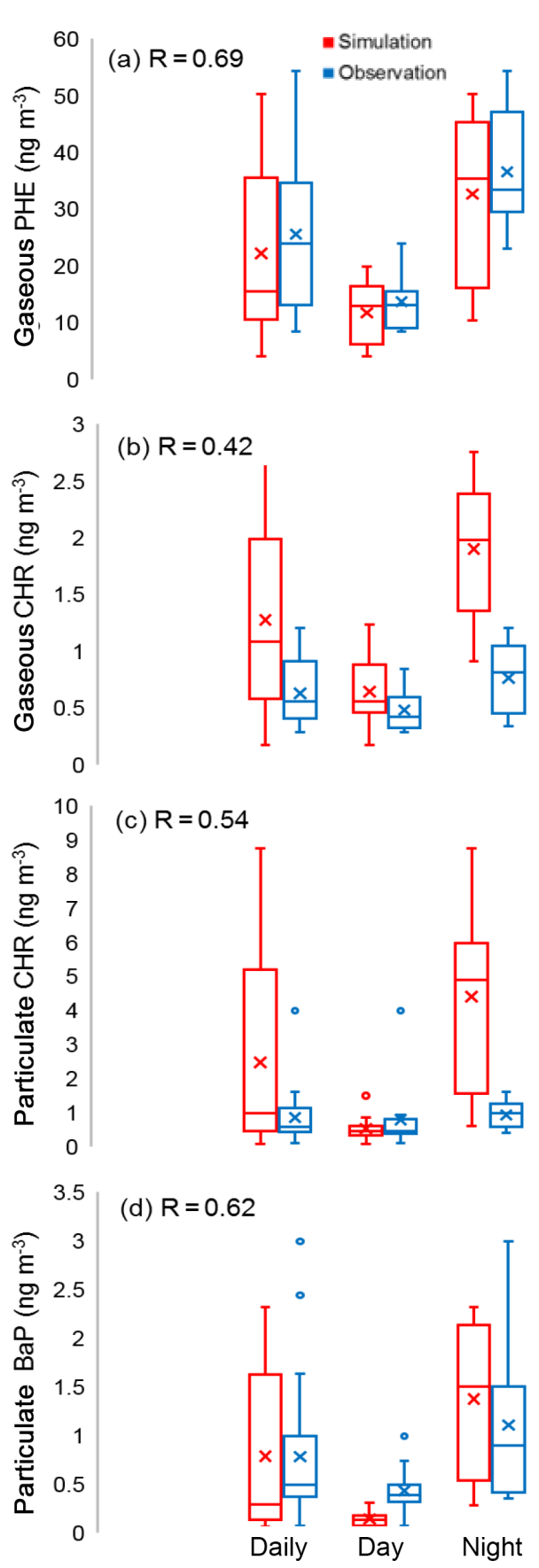

Figure 3. Simulated (red) and observed (blue) concentrations of (a) gaseous PHE, (b) gaseous CHR, (c) particulate CHR and (d) particulate $\mathrm{BaP}$ at the Xianghe site averaged over 1122 July 2013. The line and " $X$ " in each box are the median and mean, while the boxes represent the 25 th and 75 th percentiles. Upper whisker is quartile $3(\mathrm{Q} 3)+1.5 \times$ interquartile range $(\mathrm{IQR})$ or maximum value, whichever is smaller; lower whisker is quartile $1(\mathrm{Q} 1)-1.5 \times \mathrm{IQR}$ or minimum value, whichever is larger. The Spearman's rank correlation coefficients $R$ use combined daytime and nighttime data sets. 


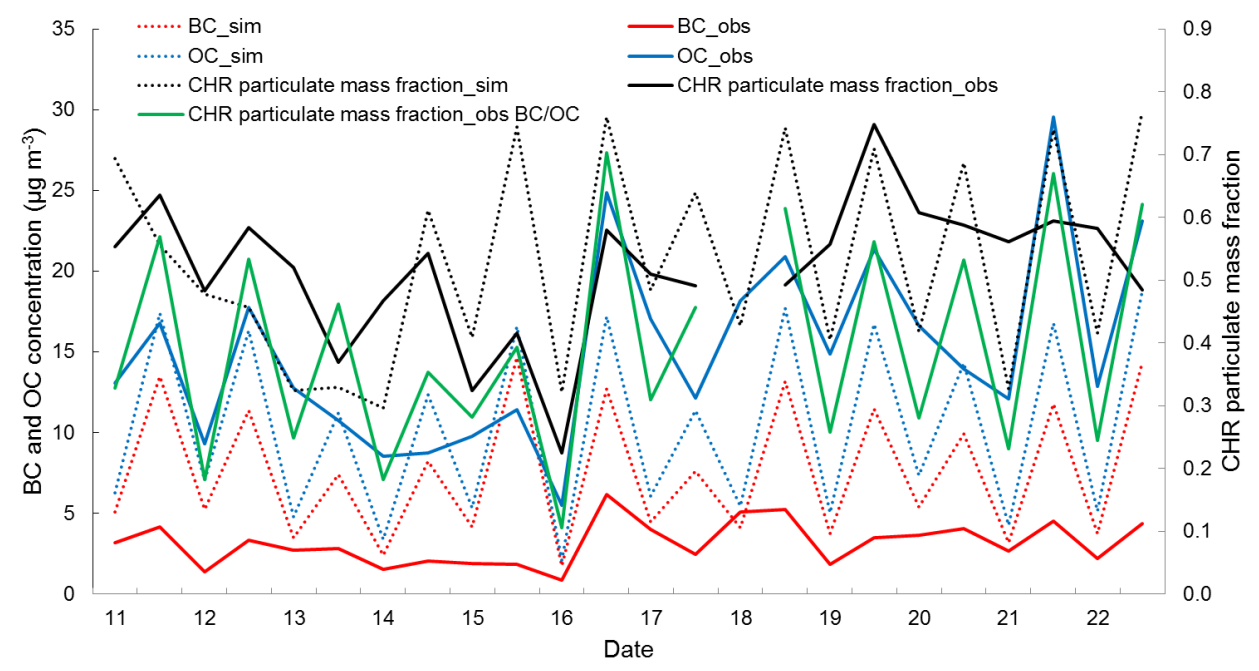

Figure 4. Simulated and observed BC, OC and particulate mass fraction of CHR at the Xianghe site during 11-22 July 2013 (10 h means). Calculated particulate mass fraction of CHR based on observed BC and $\mathrm{OC}$ is shown at the green solid line. Calculation explained in the text.

with $0.30-0.58$ in Beijing (Xianghe is a semi-urban town in the Beijing metropolitan area) by Inomata et al. (2012). This demonstrates the model's good capability in predicting the vertical and horizontal transport of PAH. The simulated gas-phase PHE has the best correlation rate of 0.69 and also the best predicted average concentrations among the other PAH species (Fig. 3). The model well catches the observed daily average concentration of particulate $\mathrm{BaP}(\mathrm{ob}-$ served $0.78 \mathrm{ng} \mathrm{m}^{-3}$, simulated $0.78 \mathrm{ng} \mathrm{m}^{-3}$ ), while Inomata et al. (2012) underestimated daily concentration of $\mathrm{BaP}$ in Beijing by about a factor of 2 . The night and day mean levels of particulate $\mathrm{BaP}, 1.10$ and $0.43 \mathrm{ng} \mathrm{m}^{-3}$, respectively, are predicted as 1.37 and $0.14 \mathrm{ng} \mathrm{m}^{-3}$, respectively. Both predicted gas- and particulate-phase CHR are overestimated (Fig. 3b-c). Further diurnal comparisons reveal that such overestimate of daily CHR concentrations mainly comes from nighttime rather than daytime (Table S3). One reason may be that the same hourly, monthly and annual scaling factors of CHR emissions are applied all over the domain. Furthermore, as partitioning strongly influences atmospheric lifetime, the bias in predicted particulate mass fraction $(\theta)$ can lead to the bias in predicted concentrations of CHR.

Although the simulated absolute values of $\theta$ are close to the measured values (black solid and dotted lines in Fig. 4): the observed (simulated) average particulate mass fraction, is $0.52(0.53)$ for $24 \mathrm{~h}, 0.49(0.42)$ for daytime and 0.54 $(0.65)$ for nighttime. The prediction might shield the fact of the overestimated $\mathrm{OC}$ and compensating underestimated $\mathrm{BC}$ concentrations (blue and red lines in Fig. 4). When applying the gas-particle partitioning parameterisations to the measured OC and BC concentrations, slightly lower than observed is predicted, but the correlation of simulated and observed $\theta$ is significantly improved, from $r=0.31$ to $r=0.74$ (green line in Fig. 4) when the simulated bias in OC/BC concentration is eliminated. It also implies that adsorption to $\mathrm{BC}$ is more important than absorption by $\mathrm{OC}$ in determining partitioning, and that the partitioning scheme used in this model is suitable for this East Asian source area.

Overall, the model is found to predict the diurnal variations of PAH concentrations and particulate mass fractions reasonably well at the suburban site in the source region.

\subsubsection{Evaluation of the Asian outflow}

$\mathrm{PAH}$ predictions at remote sites are more challenging as the uncertainties in chemistry and gas-particle partitioning propagate. Model validation so far had been limited to seasonal features (Zhang et al., 2011a, b), while higher temporal features had not been addressed yet. For example, discrepancies of a factor of 16-476 between predicted and observed average PAH (BaP, CHR, BbF, BkF, IcdP, DahA, BghiP) concentrations at the Waliguan site, a continental background site for ambient air monitoring in western China, were found much larger than at urban or suburban sites (Zhang et al., 2009). In our study, the predicted concentration levels in the Gosan winter case agree well with observations: the observed (simulated) average concentrations of PAHs are 0.020 (0.022) $\mathrm{ng} \mathrm{m}^{-3}$ for particulate BaP, 0.81 (1.73) $\mathrm{ng} \mathrm{m}^{-3}$ for gaseous PHE, $0.029(0.029) \mathrm{ng} \mathrm{m}^{-3}$ for gaseous CHR and $0.45(0.24) \mathrm{ng} \mathrm{m}^{-3}$ for particulate CHR (Fig. 5, Table S4). Compared with previous studies, our simulated average concentrations of $\mathrm{BaP}$ agreed well with the observation (deviation $<10 \%$ ), while Zhang et al. (2011a) underestimated $\mathrm{BaP}$ by about $50 \%$. For the Gosan summer case, our simulated average $\mathrm{BaP}$ concentration is $0.006 \mathrm{ng} \mathrm{m}^{-3}$ (Fig. S6), much closer to the observed value of $0.012 \mathrm{ng} \mathrm{m}^{-3}$ than the simulated $\mathrm{BaP}$ concentration of $\approx 0.001 \mathrm{ng} \mathrm{m}^{-3}$ by Zhang 

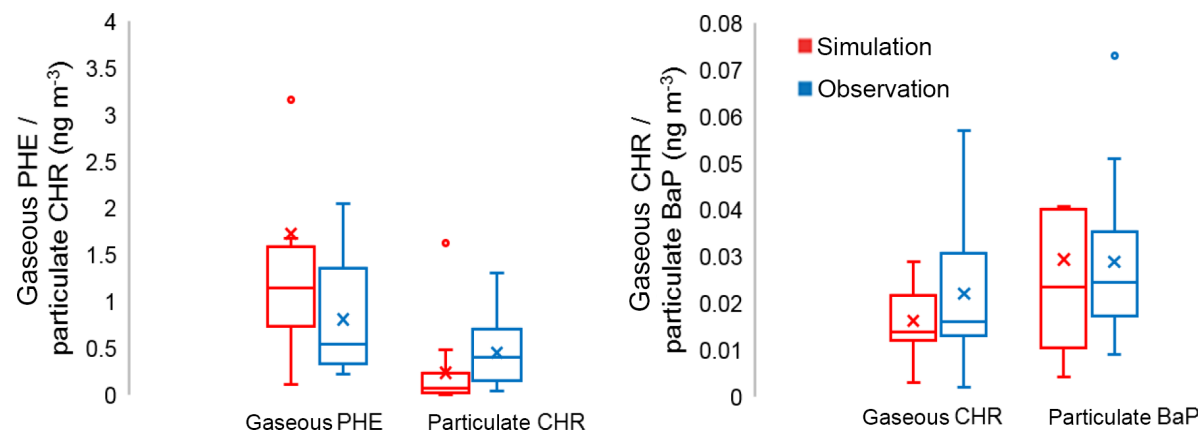

Figure 5. Simulated (red) and observed (blue) concentrations of gaseous PHE, particulate CHR, gaseous CHR and particulate BaP at the Gosan site averaged over 14-25 February 2003. The line and " $X$ " in each box are the median and mean, while the boxes represent the 25th and 75th percentiles. Upper whisker is quartile $3(\mathrm{Q} 3)+1.5 \times$ interquartile range (IQR) or maximum value, whichever is smaller; lower whisker is quartile $1(\mathrm{Q} 1)-1.5 \times \mathrm{IQR}$ or minimum value, whichever is larger.

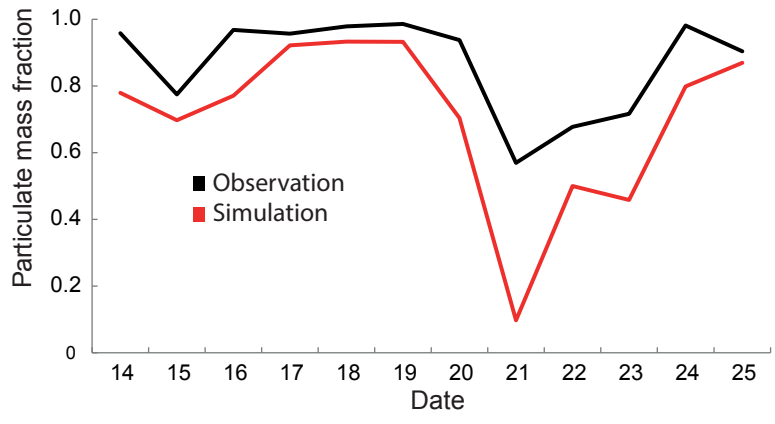

Figure 6. Simulated and observed daily averaged particulate mass fraction of CHR at the Gosan site during 14-25 February 2003.

et al. (2011a). In general, WRF-Chem-PAH model shows good/reasonable agreement with observations in both winter and summer seasons. However, it is worth noting that although the daily average concentration levels of PAHs are reasonably well simulated, the diurnal variations are not well captured at the remote back ground site Gosan (Fig. S5).

The correlation of observed and simulated daily average CHR particulate mass fractions in the Gosan winter case is high ( $r=0.73$; see Fig. 6$)$. The correlation is significantly lower at the Xianghe site $(r=0.37)$, which may due to the proximity to sources. The phase equilibrium of CHR may not be established shortly after emission and the model may not resolve its spatial gradients. An underestimation of simulated particulate mass fraction can be seen in the both winter and summer cases (Figs. 6 and S6). Such underestimation may be caused by the combined effects of uncertainties, such as the emission, degradation, dry/wet deposition and the long-range transport of OC/BC.

These results suggest that our newly developed WRFChem-PAH is reasonably accurate in simulating the concentration levels and particulate mass fractions of PAHs for the Asian outflow.

\subsection{Distributions of PAHs in East Asia}

To illustrate the PAHs distribution in East Asia in both summer and wintertime, Fig. 7 shows the surface concentrations of three representative PAHs averaged over summer 11-22 July 2013 and winter 14-25 February 2003 simulation periods. Another simulation period 6-17 June 2003 agrees with the period 11-22 July 2013 in reflecting summer time distribution characteristics. The lifetimes of PAH over eastern China $\left(20-42^{\circ} \mathrm{N}, 107-122^{\circ} \mathrm{E}\right.$, mainland China) are $1.5-9 \mathrm{~h}$ for PHE, $2-11 \mathrm{~h}$ for CHR, $2 \mathrm{~h}-3$ days for BaP in summer and $9.5 \mathrm{~h}-3.5$ days for PHE, $11 \mathrm{~h}-4.5$ days for CHR, 1.5-6.5 days for BaP in winter, respectively. Due to the relatively short lifetime of PAH species, the spatial distribution of PAH concentrations in the atmosphere is dominated largely by local emissions (Hafner et al., 2005) and the concentration of PAH decreases rapidly away from the source regions. There is a major eastward transport and outflow pathway that plumes with high levels of PAHs from the eastern part of China are swept to the East China Sea and further to the western Pacific Ocean. The simulated average concentration of $0.006 \mathrm{ng} \mathrm{m}^{-3}$ for particulate $\mathrm{BaP}$ during 14 25 February 2003 at a monitoring background site $\left(26.19^{\circ} \mathrm{N}\right.$, $127.75^{\circ} \mathrm{E}$ ) in Okinawa, Japan, which is located on the outflow pathway from China, is close to the monthly-averaged observation value $0.013 \mathrm{ng} \mathrm{m}^{-3}$ (http://tenbou.nies.go.jp/gis/ monitor/). The concentrations of PAHs are higher in winter than summer, mainly due to higher emissions and slower degradation rates.

The model-calculated mean particulate mass fractions are also shown in Fig. 7. The particulate mass fractions are higher in winter than in summer and in North China than in other regions. This is largely due to the distribution of $\mathrm{OC} / \mathrm{BC}$ concentrations (high in North China), and seasonal and latitudinal variation of temperature. PHE has extremely small particulate mass fractions, while $\theta \mathrm{BaP} \approx 1$ over most of China in winter but only $95 \%$ over North China in summer. On the other hand, CHR shows the largest spatial and 

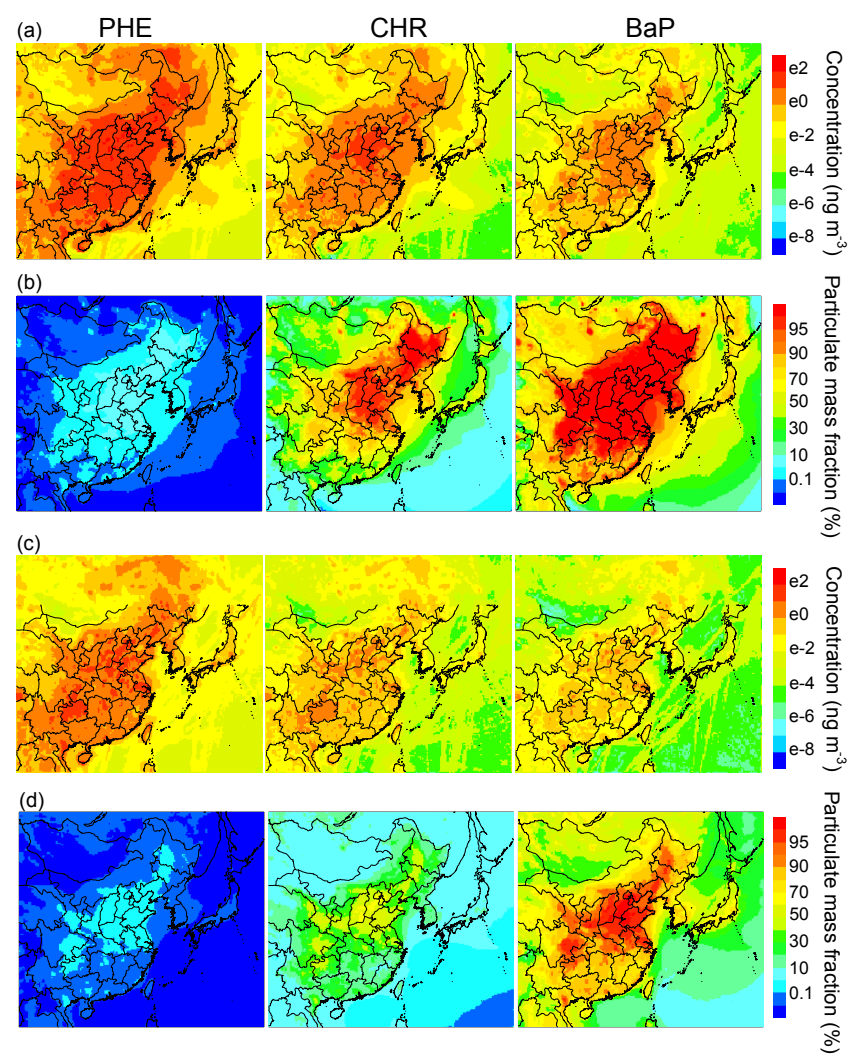

Figure 7. Simulated (a) surface concentrations and (b) particulate mass fractions of PHE, CHR and BaP averaged over 14-25 February 2003. Simulated (c) surface concentrations and (d) particulate mass fractions of PHE, CHR and $\mathrm{BaP}$ averaged over 1122 July 2013.

seasonal variations among these three compounds. Our predicted PAH distributions and particulate mass fractions generally agree with the previous studies in East Asia (Zhang et al., 2011b; Inomata et al., 2012).

\section{Significance of PAH heterogeneous reaction with ozone and gas-phase reaction with nitrate radical}

We test the impact of heterogeneous and homogeneous reaction of $\mathrm{BaP}$, as well as $\mathrm{NO}_{3}$ gas reactions of CHR and PHE. In other model studies of PAHs, these processes were usually neglected (Zhang et al., 2011a, b).

As shown in Fig. 8, the simulation without any $\mathrm{BaP}$ reaction significantly overestimates the average concentration of BaP. Compared with the kinetic model scheme, the model-calculated $\mathrm{BaP}$ concentration increased from 0.14 to $1.32 \mathrm{ng} \mathrm{m}^{-3}$ for daytime, 1.37 to $2.86 \mathrm{ng} \mathrm{m}^{-3}$ for nighttime and 0.78 to $2.09 \mathrm{ng} \mathrm{m}^{-3}$ for the whole day, which move further away from the observed daily average of $0.78 \mathrm{ng} \mathrm{m}^{-3}$ (Fig. 8). Furthermore, the homogeneous gas-phase reaction of $\mathrm{BaP}$ is of negligible efficiency as compared to the het-

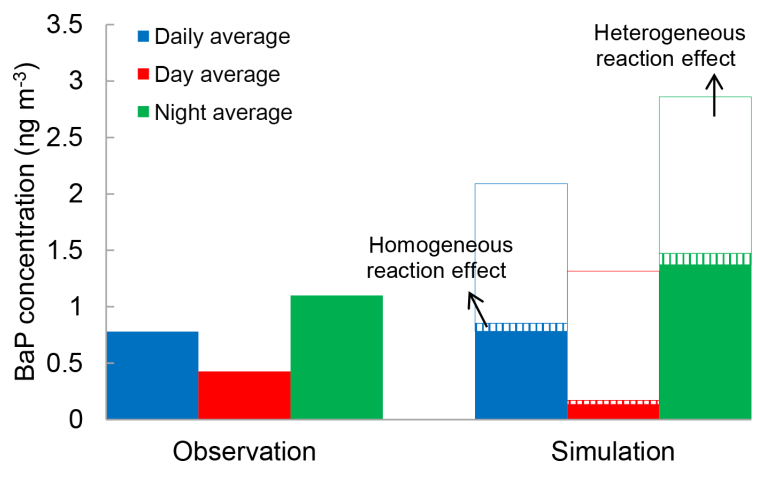

Figure 8. Simulated concentrations of $\mathrm{BaP}$ compared with observation at the Xianghe site during 11-22 July 2013. The contributions of heterogeneous and homogeneous reaction are shown are shown as blank areas and as small vertical bars, respectively, in the simulation bars.

erogeneous reaction. This confirms that $\mathrm{BaP}$ heterogeneous degradation is indispensable. A companion manuscript discussing the comparison of different heterogeneous degradation schemes is now in preparation.

Figure 9 shows the simulated concentrations of gas-phase PHE and gas- and particulate-phase CHR with and without $\mathrm{NO}_{3}$ gas-phase reactions compared with observations at the Xianghe site. It is found that during nights with high $\mathrm{NO}_{3}$ (48.5 and $43.0 \mathrm{ng} \mathrm{m}^{-3}$, or $\approx 18$ and $\approx 16 \mathrm{pptv}$ as the $10 \mathrm{~h}$ mean, $12-14$ July) the $\mathrm{NO}_{3}$ reaction causes a significant nighttime drop of PAH levels, i.e. PHE and CHR by $\approx-50 \%$ and -50 to $-75 \%$, respectively. This is surprisingly drastic for PHE regarding the rate coefficient, $k_{\mathrm{NO}_{3}}=$ $1.2 \times 10^{-13} \mathrm{~cm}^{3} \mathrm{molec}^{-1} \mathrm{~s}^{-1}$ (Table 1), corresponding to a lifetime of $\tau_{\mathrm{NO}_{3}} \approx 5 \mathrm{~h}$, but $\tau_{\mathrm{NO}_{3}} \approx 10 \mathrm{~min}$ for $\mathrm{CHR}\left(k_{\mathrm{NO}_{3}}=\right.$ $4.0 \times 10^{-12} \mathrm{~cm}^{3} \mathrm{molec}^{-1} \mathrm{~s}^{-1}$, Table 1). The impact on the concentration of particulate-phase CHR is as significant as gas-phase CHR at night.

\section{Conclusions and discussion}

We have developed the WRF-Chem-PAH model based on the WRF-Chem model to simulate the atmospheric fate of volatile, semivolatile and non-volatile PAH compounds. The implemented state-of-the-art processes for PAHs are gas-particle partitioning, air-soil gas exchange, homogeneous gas-phase and heterogeneous reactions, cloud scavenging, dry and wet deposition, advective transport and cumulus convection. The simulated PAHs in our current WRFChem-PAH model include PHE, CHR and BaP, representing volatile, semivolatile and non-volatile PAH compounds, respectively. Also, the model can be applied for any similar semivolatile trace organic compound.

The model has been applied for East Asia. The model predicts observations (both atmospheric concentration of PAHs and the particulate mass fraction of semivolatile CHR) at 

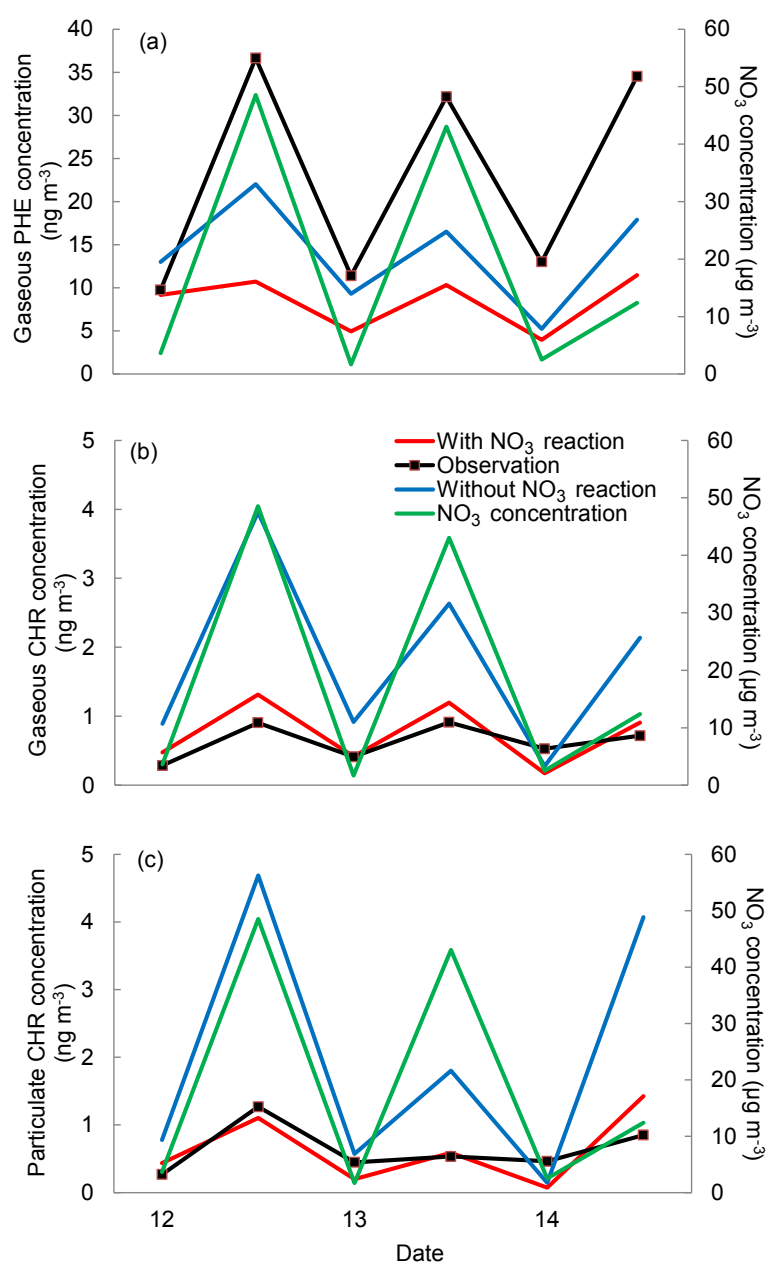

Figure 9. Simulated concentrations of (a) gaseous PHE, (b) gaseous $\mathrm{CHR}$ and (c) particulate $\mathrm{CHR}$ with and without reactions of $\mathrm{NO}_{3}$ compared with observation and simulated concentrations of $\mathrm{NO}_{3}$ during 12-14 July 2013.

both a near-source and remote site in the continental outflow reasonably well considering big uncertainties in our current knowledge, most notably with regard to the emission, gasparticle partitioning and atmospheric chemistry.

Both the testing of heterogeneous $\mathrm{O}_{3}$ reaction and the homogeneous $\mathrm{NO}_{3}$ reaction emphasise the importance of these reactions for the fate and distributions of the selected PAHs in the polluted atmospheric environment. PAH modelling should include these reactions to better assess the fate and the distributions in polluted and remote environments. However, chemical kinetic measurement and understanding of pathways are limited, in particular for semivolatile species and for heterogeneous chemistry in general (Keyte et al., 2013). Intensive laboratory studies covering semivolatile PAHs, various aerosol matrices, and scenarios of particle mixing and aging are needed to improve PAH modelling.

The model accounts for secondary PAH emissions, i.e. re-volatilisation from soil (semivolatile PAHs only). These emissions add to the pollutant distributions. However, as a consequence of prevailing westerly winds in combination with emissions being concentrated in eastern China, unlike in South Asia (very little emissions in areas east of northeastern India and Bangladesh) and other continents (Lammel et al., 2009; Galarneau et al., 2014), there is a large geographical overlap between secondary sources and primary sources over East Asia. Secondary emissions (re-volatilisation) from the sea surface of the Yellow Sea and the adjacent shelf areas (East and South China seas) also influence the regional PAH distributions over the mainland. This was not addressed in this study (process not included) and should be investigated in order to better assess trans-Pacific transport of PAHs and their even more toxic metabolites, nitro-PAHs (Zhang et al., 2011a).

Data availability. The observation data and code of this study are available from the corresponding author upon reasonable request.

\section{The Supplement related to this article is available online at https://doi.org/10.5194/acp-17-12253-2017- supplement.}

Author contributions. YFC, GL, UP, and HS and conceived the study. QM did model development, case simulation, data processing and visualisation. MS, YFC, HS and UP developed the new heterogeneous degradation scheme for model implementation. CNG and IMH provided the code of WRF-Chem-Hg (Gencarelli et al., 2014) and helped with model development. YC contributed to data processing. PP, MT, YXZ, GJZ, DvP, QZ and HH provided the observation data at the Xianghe site. YFC, QM, GL, HS, UP and PS discussed the results. QM, YFC, GL and UP wrote the manuscript.

Competing interests. The authors declare that they have no conflict of interest.

Acknowledgements. This work is supported by the Max Planck Society. The work of Yafang Cheng and Hang Su is also supported by the National Natural Science Foundation of China (41330635). We thank Young-Sung Ghim for providing the Gosan measurement data. We thank Georg Grell and Bill Skamarock for the explanation of WRF-Chem transport scheme. The coding work is supported by Yvlu Qiu, Feng Wang, Mega Octaviani, Tabish Ansari, Chao Wei and Stephan Nordmann. The description of the Xianghe sampling is supported by Pourya Shahpoury. We also thank Huizhong Shen, Rong Wang, Ye Huang, Fumo Yang and Pasquale Sellitto for valuable comments.

The article processing charges for this open-access publication were covered by the Max Planck Society.

Edited by: Ronald Cohen

Reviewed by: two anonymous referees 


\section{References}

Ackermann, I. J., Hass, H., Memmesheimer, M., Ebel, A., Binkowski, F. S., and Shankar, U.: Modal aerosol dynamics model for Europe: Development and first applications, Atmos. Environ., 32, 2981-2999, 10.1016/S1352-2310(98)000065, 1998.

Andersson, J. T. and Achten, C.: Time to Say Goodbye to the 16 EPA PAHs? Toward an Up-to-Date Use of PACs for Environmental Purposes, Polycycl. Aromat. Comp., 35, 330-354, https://doi.org/10.1080/10406638.2014.991042, 2015.

Atkinson, R., Baulch, D. L., Cox, R. A., Hampson, R. F., Kerr, J. A., and Troe, J.: Evaluated Kinetic and Photochemical Data for Atmospheric Chemistry - Supplement-Iii, Int. J. Chem. Kinet., 21, 115-150, https://doi.org/10.1002/kin.550210205, 1989.

Aulinger, A., Matthias, V., and Quante, M.: Introducing a partitioning mechanism for PAHs into the Community Multiscale Air Quality modeling system and its application to simulating the transport of benzo(a) pyrene over Europe, J. Appl. Meteorol. Clim., 46, 1718-1730, https://doi.org/10.1175/2007jamc1395.1, 2007.

Bamford, H. A., Poster, D. L., and Baker, J. E.: Temperature dependence of Henry's law constants of thirteen polycyclic aromatic hydrocarbons between $4{ }^{\circ} \mathrm{C}$ and $31^{\circ} \mathrm{C}$, Environ. Toxicol. Chem., 18, 1905-1912, https://doi.org/10.1002/etc.5620180906, 1999.

Berkemeier, T., Steimer, S. S., Krieger, U. K., Peter, T., Pöschl, U., Ammann, M., and Shiraiwa, M.: Ozone uptake on glassy, semi-solid and liquid organic matter and the role of reactive oxygen intermediates in atmospheric aerosol chemistry, Phys. Chem. Chem. Phys., 18, 12662-12674, https://doi.org/10.1039/c6cp00634e, 2016.

Bieser, J., Aulinger, A., Matthias, V., and Quante, M.: Impact of Emission Reductions between 1980 and 2020 on Atmospheric Benzo[a]pyrene Concentrations over Europe, Water Air Soil Poll., 223, 1393-1414, https://doi.org/10.1007/s11270-0110953-z, 2012.

Binkowski, F. S. and Roselle, S. J.: Models-3 community multiscale air quality (CMAQ) model aerosol component - 1. Model description, J. Geophys. Res., 108, 4183, https://doi.org/10.1029/2001jd001409, 2003.

Chen, F. and Dudhia, J.: Coupling an advanced land surfacehydrology model with the Penn State-NCAR MM5 modeling system. Part I: Model implementation and sensitivity, Mon. Weather. Rev., 129, 569-585, https://doi.org/10.1175/15200493(2001)129<0569:Caalsh>2.0.Co;2, 2001.

Chou, M. and Suarez, M.: An efficient thermal infrared radiation parameterization for use in general circulation models, NASA Tech. Memo, 104606, 85 pp., 1994.

Dachs, J. and Eisenreich, S. J.: Adsorption onto aerosol soot carbon dominates gas-particle partitioning of polycyclic aromatic hydrocarbons, Environ. Sci. Technol., 34, 3690-3697, https://doi.org/10.1021/Es991201+, 2000.

Darmenov, A. S. and Silva, A. D.: The Quick Fire Emissions Dataset (QFED) - Documentation of versions 2.1, 2.2 and 2.4, NASA Technical Report Series on Global Modeling and Data Assimilation, 32, 1-183, 2013.

Efstathiou, C. I., Matejovicová, J., Bieser, J., and Lammel, G.: Evaluation of gas-particle partitioning in a regional air quality model for organic pollutants, Atmos. Chem. Phys., 16, 15327-15345, https://doi.org/10.5194/acp-16-15327-2016, 2016.
Emmons, L. K., Walters, S., Hess, P. G., Lamarque, J.-F., Pfister, G. G., Fillmore, D., Granier, C., Guenther, A., Kinnison, D., Laepple, T., Orlando, J., Tie, X., Tyndall, G., Wiedinmyer, C., Baughcum, S. L., and Kloster, S.: Description and evaluation of the Model for Ozone and Related chemical Tracers, version 4 (MOZART-4), Geosci. Model Dev., 3, 43-67, https://doi.org/10.5194/gmd-3-43-2010, 2010.

Friedman, C. L. and Selin, N. E.: Long-Range Atmospheric Transport of Polycyclic Aromatic Hydrocarbons: A Global 3-D Model Analysis Including Evaluation of Arctic Sources, Environ. Sci. Technol., 46, 9501-9510, https://doi.org/10.1021/Es301904d, 2012.

Friedman, C. L., Pierce, J. R., and Selin, N. E.: Assessing the Influence of Secondary Organic versus Primary Carbonaceous Aerosols on Long-Range Atmospheric Polycyclic Aromatic Hydrocarbon Transport, Environ. Sci. Technol., 48, 3293-3302, https://doi.org/10.1021/Es405219r, 2014a.

Friedman, C. L., Zhang, Y. X., and Selin, N. E.: Climate Change and Emissions Impacts on Atmospheric PAH Transport to the Arctic, Environ. Sci. Technol., 48, 429-437, https://doi.org/10.1021/Es403098w, 2014b.

Galarneau, E., Makar, P. A., Sassi, M., and Diamond, M. L.: Estimation of atmospheric emissions of six semivolatile polycyclic aromatic hydrocarbons in southern Canada and the United States by use of an emissions processing system, Environ. Sci. Technol., 41, 4205-4213, https://doi.org/10.1021/Es062303k, 2007.

Galarneau, E., Makar, P. A., Zheng, Q., Narayan, J., Zhang, J., Moran, M. D., Bari, M. A., Pathela, S., Chen, A., and Chlumsky, R.: PAH concentrations simulated with the AURAMSPAH chemical transport model over Canada and the USA, Atmos. Chem. Phys., 14, 4065-4077, https://doi.org/10.5194/acp14-4065-2014, 2014.

Gencarelli, C. N., De Simone, F., Hedgecock, I. M., Sprovieri, F., and Pirrone, N.: Development and application of a regional-scale atmospheric mercury model based on WRF/Chem: a Mediterranean area investigation, Environ. Sci. Pollut. R., 21, 40954109, https://doi.org/10.1007/s11356-013-2162-3, 2014.

Grell, G. A. and Devenyi, D.: A generalized approach to parameterizing convection combining ensemble and data assimilation techniques, Geophys. Res. Lett., 29, 1693, https://doi.org/10.1029/2002gl015311, 2002.

Grell, G. A., Peckham, S. E., Schmitz, R., McKeen, S. A., Frost, G., Skamarock, W. C., and Eder, B.: Fully coupled "online" chemistry within the WRF model, Atmos. Environ., 39, 6957-6975, https://doi.org/10.1016/j.atmosenv.2005.04.027, 2005.

Guenther, A., Karl, T., Harley, P., Wiedinmyer, C., Palmer, P. I., and Geron, C.: Estimates of global terrestrial isoprene emissions using MEGAN (Model of Emissions of Gases and Aerosols from Nature), Atmos. Chem. Phys., 6, 3181-3210, https://doi.org/10.5194/acp-6-3181-2006, 2006.

Hafner, W. D., Carlson, D. L., and Hites, R. A.: Influence of local human population on atmospheric polycyclic aromatic hydrocarbon concentrations, Environ. Sci. Technol., 39, 7374-7379, https://doi.org/10.1021/es0508673, 2005.

Halsall, C. J., Sweetman, A. J., Barrie, L. A., and Jones, K. C.: Modelling the behaviour of PAHs during atmospheric transport from the UK to the Arctic, Atmos. Environ., 35, 255-267, https://doi.org/10.1016/S1352-2310(00)00195-3, 2001. 
Han, J. S., Moon, K. J., Lee, S. J., Kim, Y. J., Ryu, S. Y., Cliff, S. S., and Yi, S. M.: Size-resolved source apportionment of ambient particles by positive matrix factorization at Gosan background site in East Asia, Atmos. Chem. Phys., 6, 211-223, https://doi.org/10.5194/acp-6-211-2006, 2006.

Hung, H., Blanchard, P., Halsall, C. J., Bidleman, T. F., Stern, G. A., Fellin, P., Muir, D. C. G., Barrie, L. A., Jantunen, L. M., Helm, P. A., Ma, J., and Konoplev, A.: Temporal and spatial variabilities of atmospheric polychlorinated biphenyls (PCBs), organochlorine (OC) pesticides and polycyclic aromatic hydrocarbons (PAHs) in the Canadian Arctic: Results from a decade of monitoring, Sci. Total Environ., 342, 119-144, https://doi.org/10.1016/j.scitotenv.2004.12.058, 2005.

Hylland, K.: Polycyclic aromatic hydrocarbon (PAH) ecotoxicology in marine ecosystems, J. Toxicol. Env. Heal. A., 69, 109-123, https://doi.org/10.1080/15287390500259327, 2006.

Inomata, Y., Kajino, M., Sato, K., Ohara, T., Kurokawa, J. I., Ueda, H., Tang, N., Hayakawa, K., Ohizumi, T., and Akimoto, H.: Emission and Atmospheric Transport of Particulate PAHs in Northeast Asia, Environ. Sci. Technol., 46, 4941-4949, https://doi.org/10.1021/Es300391w, 2012.

Inomata, Y., Kajino, M., Sato, K., Ohara, T., Kurokawa, J., Ueda, H., Tang, N., Hayakawa, K., Ohizumi, T., and Akimoto, H.: Source contribution analysis of surface particulate polycyclic aromatic hydrocarbon concentrations in northeastern Asia by source-receptor relationships, Environ. Pollut., 182, 324-334, https://doi.org/10.1016/j.envpol.2013.07.020, 2013.

Janjic, Z. I.: The Step-Mountain Eta Coordinate Model - Further Developments of the Convection, Viscous Sublayer, and Turbulence Closure Schemes, Mon. Weather. Rev., 122, 927-945, https://doi.org/10.1175/15200493(1994)122<0927:Tsmecm>2.0.Co;2, 1994.

Jonker, M. T. O. and Koelmans, A. A.: Sorption of Polycyclic Aromatic Hydrocarbons and Polychlorinated Biphenyls to Soot and Soot-like Materials in the Aqueous Environment: Mechanistic Considerations, Environ. Sci. Technol., 36, 3725-3734, https://doi.org/10.1021/es020019x, 2002.

Jury, W. A., Spencer, W. F., and Farmer, W. J.: Behavior Assessment Model for Trace Organics in Soil .1. Model Description, J. Environ. Qual., 12, 558-564, 1983.

Karickhoff, S. W.: Semi-empirical estimation of sorption of hydrophobic pollutants on natural sediments and soils, Chemosphere, 10, 833-846, 1981.

Keyte, I. J., Harrison, R. M., and Lammel, G.: Chemical reactivity and long-range transport potential of polycyclic aromatic hydrocarbons - a review, Chem. Soc. Rev., 42, 9333-9391, https://doi.org/10.1039/C3cs60147a, 2013.

Kim, J. Y., Ghim, Y. S., Song, C. H., Yoon, S. C., and Han, J. S.: Seasonal characteristics of air masses arriving at Gosan, Korea, using fine particle measurements between November 2001 and August 2003, J. Geophys. Res.-Atmos., 112, D07202, https://doi.org/10.1029/2005jd006946, 2007.

Kim, J. Y., Lee, J. Y., Choi, S. D., Kim, Y. P., and Ghim, Y. S.: Gaseous and particulate polycyclic aromatic hydrocarbons at the Gosan background site in East Asia, Atmos. Environ., 49, 311319, https://doi.org/10.1016/j.atmosenv.2011.11.029, 2012.

Klöpffer, W., Wagner, B. O., and Steinhäuser, K. G.: Atmospheric Degradation of Organic Substances: Persistence, Transport Potential, Spatial Range, Wiley, 2008.
Kwok, E. S. C., Harger, W. P., Arey, J., and Atkinson, R.: Reactions of Gas-Phase Phenanthrene under Simulated Atmospheric Conditions, Environ. Sci. Technol., 28, 521-527, https://doi.org/10.1021/es00052a027, 1994.

Lammel, G., Sehili, A. M., Bond, T. C., Feichter, J., and Grassl, H.: Gas/particle partitioning and global distribution of polycyclic aromatic hydrocarbons - A modelling approach, Chemosphere, 76, 98-106, https://doi.org/10.1016/j.chemosphere.2009.02.017, 2009.

Lang, C., Tao, S., Zhang, G., Fu, J., and Simonich, S.: Outflow of polycyclic aromatic hydrocarbons from Guangdong, Southern China, Environ. Sci. Technol., 41, 8370-8375, https://doi.org/10.1021/es071853v, 2007.

Lang, C., Tao, S., Liu, W. X., Zhang, Y. X., and Simonich, S.: Atmospheric transport and outflow of polycyclic aromatic hydrocarbons from China, Environ. Sci. Technol., 42, 5196-5201, https://doi.org/10.1021/Es800453n, 2008.

Liao, J., Wang, T., Wang, X., Xie, M., Jiang, Z., Huang, X., and Zhu, J.: Impacts of different urban canopy schemes in WRF/Chem on regional climate and air quality in Yangtze River Delta, China, Atmos. Res., 145-146, 226-243, https://doi.org/10.1016/j.atmosres.2014.04.005, 2014.

Lin, Y.-L., Farley, R. D., and Orville, H. D.: Bulk Parameterization of the Snow Field in a Cloud Model, J. Clim Appl. Meteorol., 22, 1065-1092, https://doi.org/10.1175/1520 0450(1983)022<1065:BPOTSF>2.0.CO;2, 1983.

Lohmann, R. and Lammel, G.: Adsorptive and absorptive contributions to the gas-particle partitioning of polycyclic aromatic hydrocarbons: State of knowledge and recommended parametrization for modeling, Environ. Sci. Technol., 38, 3793-3803, https://doi.org/10.1021/Es035337q, 2004.

Lu, P. Y., Metcalf, R. L., Plummer, N., and Mandel, D.: The environmental fate of three carcinogens: Benzo- $(\alpha)$ pyrene, benzidine, and vinyl chloride evaluated in laboratory model ecosystems, Arch. Environ. Con. Tox., 6, 129-142, https://doi.org/10.1007/BF02097756, 1977.

Lu, Z., Zhang, Q., and Streets, D. G.: Sulfur dioxide and primary carbonaceous aerosol emissions in China and India, 1996-2010, Atmos. Chem. Phys., 11, 9839-9864, https://doi.org/10.5194/acp-11-9839-2011, 2011.

Lv, Y., Li, X., Xu, T. T., Cheng, T. T., Yang, X., Chen, J. M., Iinuma, Y., and Herrmann, H.: Size distributions of polycyclic aromatic hydrocarbons in urban atmosphere: sorption mechanism and source contributions to respiratory deposition, Atmos. Chem. Phys., 16, 2971-2983, https://doi.org/10.5194/acp16-2971-2016, 2016.

Mackay, D. and Paterson, S.: Evaluating the multimedia fate of organic chemicals: a level III fugacity model, Environ. Sci. Technol., 25, 427-436, https://doi.org/10.1021/es00015a008, 1991.

Matthias, V., Aulinger, A., and Quante, M.: CMAQ simulations of the benzo(a)pyrene distribution over Europe for 2000 and 2001, Atmos. Environ., 43, 4078-4086, https://doi.org/10.1016/j.atmosenv.2009.04.058, 2009.

Mlawer, E. J., Taubman, S. J., Brown, P. D., Iacono, M. J., and Clough, S. A.: Radiative transfer for inhomogeneous atmospheres: RRTM, a validated correlated-k model for the longwave, J. Geophys. Res., 102, 16663-16682, https://doi.org/10.1029/97jd00237, 1997. 
Neu, J. L. and Prather, M. J.: Toward a more physical representation of precipitation scavenging in global chemistry models: cloud overlap and ice physics and their impact on tropospheric ozone, Atmos. Chem. Phys., 12, 3289-3310, https://doi.org/10.5194/acp-12-3289-2012, 2012.

Odabasi, M., Cetin, E., and Sofuoglu, A.: Determination of octanolair partition coefficients and supercooled liquid vapor pressures of PAHs as a function of temperature: Application to gas-particle partitioning in an urban atmosphere, Atmos. Environ., 40, 66156625, https://doi.org/10.1016/j.atmosenv.2006.05.051, 2006.

Prevedouros, K., Jones, K. C., and Sweetman, A. J.: Modelling the atmospheric fate and seasonality of polycyclic aromatic hydrocarbons in the UK, Chemosphere, 56, 195-208, https://doi.org/10.1016/j.chemosphere.2004.02.032, 2004.

Prevedouros, K., Palm-Cousins, A., Gustafsson, O., and Cousins, I. T.: Development of a black carbon-inclusive multi-media model: Application for PAHs in Stockholm, Chemosphere, 70, 607-615, https://doi.org/10.1016/j.chemosphere.2007.07.002, 2008.

Salzmann, M. and Lawrence, M.: Automatic coding of chemistry solvers in WRF-Chem using KPP, 7th WRF Users Workshop, Boulder, Colorado, USA, 2006.

San Jose, R., Perez, J. L., Callen, M. S., Lopez, J. M., and Mastral, A.: BaP (PAH) air quality modelling exercise over Zaragoza (Spain) using an adapted version of WRF-CMAQ model, Environ. Pollut., 183, 151-158, https://doi.org/10.1016/j.envpol.2013.02.025, 2013.

Sandu, A. and Sander, R.: Technical note: Simulating chemical systems in Fortran90 and Matlab with the Kinetic PreProcessor KPP-2.1, Atmos. Chem. Phys., 6, 187-195, https://doi.org/10.5194/acp-6-187-2006, 2006.

Sandu, A., Daescu, D. N., and Carmichael, G. R.: Direct and adjoint sensitivity analysis of chemical kinetic systems with KPP: Part I - theory and software tools, Atmos. Environ., 37, 5083-5096, https://doi.org/10.1016/j.atmosenv.2003.08.019, 2003.

Schell, B., Ackermann, I. J., Hass, H., Binkowski, F. S., and Ebel, A.: Modeling the formation of secondary organic aerosol within a comprehensive air quality model system, J. Geophys. Res., 106, 28275-28293, https://doi.org/10.1029/2001jd000384, 2001.

Sehili, A. M. and Lammel, G.: Global fate and distribution of polycyclic aromatic hydrocarbons emitted from Europe and Russia, Atmos. Environ., 41, 8301-8315, https://doi.org/10.1016/j.atmosenv.2007.06.050, 2007.

Shen, H. Z., Huang, Y., Wang, R., Zhu, D., Li, W., Shen, G. F., Wang, B., Zhang, Y. Y., Chen, Y. C., Lu, Y., Chen, H., Li, T. C., Sun, K., Li, B. G., Liu, W. X., Liu, J. F., and Tao, S.: Global Atmospheric Emissions of Polycyclic Aromatic Hydrocarbons from 1960 to 2008 and Future Predictions, Environ. Sci. Technol., 47, 6415-6424, https://doi.org/10.1021/Es400857z, 2013.

Shen, H. Z., Tao, S., Liu, J. F., Huang, Y., Chen, H., Li, W., Zhang, Y. Y., Chen, Y. C., Su, S., Lin, N., Xu, Y. Y., Li, B. G., Wang, X. L., and Liu, W. X.: Global lung cancer risk from PAH exposure highly depends on emission sources and individual susceptibility, Sci. Rep., 4, 6561, https://doi.org/10.1038/Srep06561, 2014.

Shiraiwa, M., Pfrang, C., and Pöschl, U.: Kinetic multi-layer model of aerosol surface and bulk chemistry (KM-SUB): the influence of interfacial transport and bulk diffusion on the oxidation of oleic acid by ozone, Atmos. Chem. Phys., 10, 3673-3691, https://doi.org/10.5194/acp-10-3673-2010, 2010.
Shiraiwa, M., Sosedova, Y., Rouviere, A., Yang, H., Zhang, Y. Y., Abbatt, J. P. D., Ammann, M., and Pöschl, U.: The role of long-lived reactive oxygen intermediates in the reaction of ozone with aerosol particles, Nat. Chem., 3, 291-295, https://doi.org/10.1038/Nchem.988, 2011.

Shrivastava, M., Lou, S., Zelenyuk, A., Easter, R. C., Corley, R. A., Thrall, B. D., Rasch, P. J., Fast, J. D., Massey Simonich, S. L., Shen, H., and Tao, S.: Global long-range transport and lung cancer risk from polycyclic aromatic hydrocarbons shielded by coatings of organic aerosol, P. Natl. Acad. Sci. USA, 114, 12461251, https://doi.org/10.1073/pnas.1618475114, 2017.

Stockwell, W. R., Kirchner, F., Kuhn, M., and Seefeld, S.: A new mechanism for regional atmospheric chemistry modeling, J. Geophys. Res., 102, 25847-25879, https://doi.org/10.1029/97jd00849, 1997.

Strand, A. and Hov, O.: A model strategy for the simulation of chlorinated hydrocarbon distributions in the global environment, Water Air Soil Poll., 86, 283-316, https://doi.org/10.1007/Bf00279163, 1996.

van Jaarsveld, J. A., VanPul, W. A. J., and DeLeeuw, F. A. A. M.: Modelling transport and deposition of persistent organic pollutants in the European region, Atmos. Environ., 31, 1011-1024, https://doi.org/10.1016/S1352-2310(96)00251-8, 1997.

Wesely, M. L.: Parameterization of Surface Resistances to Gaseous Dry Deposition in Regional-Scale Numerical-Models, Atmos. Environ., 23, 1293-1304, https://doi.org/10.1016/00046981(89)90153-4, 1989.

WHO (World Health Organization): Polynuclear aromatic hydrocarbons in Drinking-water, Background document for development of WHO Guidelines for Drinking-water Quality, Geneva, 2003.

Wild, O., Zhu, X., and Prather, M. J.: Fast-j: Accurate simulation of in- and below-cloud photolysis in tropospheric chemical models, J. Atmos. Chem., 37, 245-282, https://doi.org/10.1023/A:1006415919030, 2000.

Yaffe, D., Cohen, Y., Arey, J., and Grosovsky, A. J.: Multimedia analysis of PAHs and nitro-PAH daughter products in the Los Angeles basin, Risk Anal., 21, 275-294, https://doi.org/10.1111/0272-4332.212111, 2001.

Yahya, K., Wang, K., Campbell, P., Glotfelty, T., He, J., and Zhang, Y.: Decadal evaluation of regional climate, air quality, and their interactions over the continental US and their interactions using WRF/Chem version 3.6.1, Geosci. Model Dev., 9, 671-695, https://doi.org/10.5194/gmd-9-671-2016, 2016.

Zhang, Y. X. and Tao, S.: Seasonal variation of polycyclic aromatic hydrocarbons (PAHs) emissions in China, Environ. Pollut., 156, 657-663, https://doi.org/10.1016/j.envpol.2008.06.017, 2008.

Zhang, Y. and Tao, S.: Global atmospheric emission inventory of polycyclic aromatic hydrocarbons (PAHs) for 2004, Atmos. Environ., 43, 812-819, 2009.

Zhang, Y. X., Tao, S., Shen, H. Z., and Ma, J. M.: Inhalation exposure to ambient polycyclic aromatic hydrocarbons and lung cancer risk of Chinese population, P. Natl. Acad. Sci. USA, 106, 21063-21067, https://doi.org/10.1073/pnas.0905756106, 2009.

Zhang, Y., Pan, Y., Wang, K., Fast, J. D., and Grell, G. A.: WRF/Chem-MADRID: Incorporation of an aerosol module into WRF/Chem and its initial application to the TexAQS2000 episode, J. Geophys. Res., 115, D18202, https://doi.org/10.1029/2009jd013443, 2010. 
Zhang, Y., Tao, S., Ma, J., and Simonich, S.: Transpacific transport of benzo[a]pyrene emitted from Asia, Atmos. Chem. Phys., 11, 11993-12006, https://doi.org/10.5194/acp-11-11993-2011, 2011a.

Zhang, Y. X., Shen, H. Z., Tao, S., and Ma, J. M.: Modeling the atmospheric transport and outflow of polycyclic aromatic hydrocarbons emitted from China, Atmos. Environ., 45, 2820-2827, https://doi.org/10.1016/j.atmosenv.2011.03.006, 2011 b.
Zhang, Y., Sartelet, K., Wu, S.-Y., and Seigneur, C.: Application of WRF/Chem-MADRID and WRF/Polyphemus in Europe - Part 1: Model description, evaluation of meteorological predictions, and aerosol-meteorology interactions, Atmos. Chem. Phys., 13, 6807-6843, https://doi.org/10.5194/acp-13-6807-2013, 2013.

Zhou, S. M., Shiraiwa, M., McWhinney, R. D., Pöschl, U., and Abbatt, J. P. D.: Kinetic limitations in gas-particle reactions arising from slow diffusion in secondary organic aerosol, Faraday Discuss., 165, 391-406, https://doi.org/10.1039/C3fd00030c, 2013. 